\title{
Pre-pregnancy nutritional status and obstetric complications in pregnant adolescents
}

\author{
Diana N. De la Fuente-García1, Donato Saldivar-Rodríguez², Yolanda E. de la Garza-Casas³, \\ Cynthia K. López-Botello', Sandra M. González-Peña ${ }^{1}$, and Patricia R. Ancer-Rodríguez ${ }^{1 *}$ \\ ${ }^{1}$ Department of Nutrition Service, "Dr. José Eleuterio González" University Hospital; ${ }^{2}$ Department of Gynecology and Obstetrics, "Dr. José Eleuterio \\ González" University Hospital; ${ }^{3}$ Centro de Investigación y Desarrollo en Ciencias de la Salud (CIDICS). Universidad Autónoma de Nuevo León, \\ Monterrey, Nuevo Leon, Mexico
}

\begin{abstract}
Objective: The objective of the study was to determine if the pre-gestational nutritional status is associated with obstetric complications in pregnant adolescents who attend a third level hospital in Northeastern, Mexico. Materials and methods: Information was collected from 148 pregnant adolescents aged 12-19. Pre-gestational nutritional status was assessed through nutritional screening and obstetric complications through the clinical file provided by the Outpatient Clinic No. 5 of the Gynecology and Obstetrics Service. Results: The average age of the population was $17.4 \pm 1.34$ years. A more significant number of adolescents with malnutrition were found (34.5\% underweight and $31.8 \%$ overweight and obese). About $75 \%$ presented one or more obstetric complications, with maternal complications being the most prevalent $(66.2 \%)$. When the complications were related to pre-gestational nutritional status, significant statistical differences were observed $(p<0.05)$. Conclusion: A correct assessment of nutritional status and pre-gestational nutritional orientation is essential to promote proper feeding in adolescents before and during pregnancy to meet their nutritional needs, thus reduce the risk of obstetric complications and/or complications during childbirth.
\end{abstract}

Key words: Nutrition status. Teen pregnancy. Body mass index pre-pregnancy.

\section{Introduction}

Adolescence, according to the World Health Organization (WHO), is defined chronologically as the period between 10 and 19 years of age. It is characterized by profound and extensive physical and psychological changes, with repercussions at the personal, familial, and social levels'.

In Mexico, based on the National Health and Nutrition Survey 2012 (ENSANUT 2012 by its Spanish acronym),
$20.5 \%$ of women between the ages of 12 and 19 have become sexually active. This number is higher than that reported in the ENSANUT 2006 (14\%). Concerning adolescent pregnancy, from the total of adolescent women between 12 and 19 years of age who have had sex, $51.9 \%$ had been pregnant at one point and $10.7 \%$ were pregnant at the moment of the interview ${ }^{2}$.

Pregnancy is one of the most demanding stages in life since there are physiological changes and adaptations of the metabolism, which increase nutrient

\section{Correspondence:}

*Patricia R. Ancer-Rodríguez

E-mail: patyaner@hotmail.com
Date of reception: 06-08-2019

Date of acceptance: 22-01-2020 DOI: 10.24875/RMU.20000115
Available online: 18-06-2020
Medicina Universitaria. 2020;22(2):48-53 www.medicinauniversitaria.org

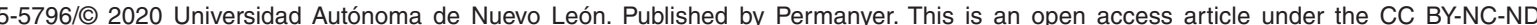
license (http://creativecommons.org/licenses/by-nc-nd/4.0/). 
utilization by the mother and the child ${ }^{3,4}$. During adolescence, pregnant women tend to follow strict, restrictive diets to avoid weight gain and hide a pregnancy. This is considered of high obstetric and perinatal risk compared to adult pregnant women ${ }^{5,6}$.

In addition, the presence of increased weight and obesity, as well as malnutrition, negatively affects adolescent pregnancy, making it more difficult to cover the increased needs during this stage ${ }^{7,8}$. There is evidence that adolescents of up to 3 or 4 years of gynecological age are still growing, so there is a fetal-maternal competition to obtain nutrients, increasing the possibilities of giving birth to an underweight newborn and/or a delay of intrauterine growth ${ }^{9-11}$.

Moreover, there is the possibility of having obstetric complications caused by prenatal exposure to drugs, an inadequate maternal diet, complications during birth, and some complications which will occur in pregnant adolescents, i.e., anemia, gestational hypertension, pre-eclampsia, and complicated abortions, among others ${ }^{12,13}$.

Therefore, the main objective of this investigation was to determine whether or not pre-gestational nutritional status is linked to obstetric complications in pregnantadolescents who attend a third-level hospital in Mexico.

\section{Materials and methods}

A transversal, observational, and descriptive study was conducted, collecting information from 148 pregnant adolescents between the ages of 12 and 19 years old who attended the Outpatient Clinic No. 5 at the Gynecology and Obstetrics Service of a third-level hospital in Mexico between August 2013 and January 2014. During this period, pre-gestational nutritional status was evaluated through nutritional screening and clinical files provided by the consult.

Sociodemographic data were obtained, including occupation, marital status, schooling, and socioeconomic status, as well as anthropometric data such as pre-gestational weight, size, and body mass index (BMI) and clinical characteristics (presence of obstetric complications). Pre-gestational nutritional status was determined using pre-gestational BMI under the criteria of the Institute of Medicine, National Academy Press, Nutrition During Pregnancy (1990), classifying it as: low weight - BMI $<19.8 \mathrm{~kg} / \mathrm{m}^{2}$, normal - BMl $>19.8-<26.0 \mathrm{~kg} / \mathrm{m}^{2}$, overweight $-\mathrm{BMI}>26.1-<29.0 \mathrm{~kg} / \mathrm{m}^{2}$, and obese $-\mathrm{BMI}$ $>29.0 \mathrm{~kg} / \mathrm{m}^{214}$.

The obstetric complications presented by the patients were classified into two groups: (1) fetal complications, including anhydramnios, ruptured membrane, cephalopelvic disproportion caused by pelvic narrowness, oligohydramnios, product with compound presentations, product with posterior urethral valves, pelvic product, transverse product, type 0 intrauterine growth restriction (IUGR), type 1 IUGR, type 4 IUGR, premature membrane rupture (PMR), macrosomia, fetal suffering, polyhydramnios, possible bowel malformation, spina bifida, and absence of nasal bone and (2) maternal complications, which include anemia, cardiac arrhythmia, asthma, asymptomatic bacteriuria, headaches, diabetic ketoacidosis, cholecystolithiasis, condyloma, constipation, diarrhea, dyspepsia, contraction dystocia, dysuria, type 1 diabetes mellitus, gestational diabetes mellitus (GDM), eclampsia, lower limb edema, multiple pregnancies, epilepsy, phosphine, hypothyroidism, herniated disc (lumbar area), gestational hypertension, carbohydrate intolerance, urinary tract infection, leucorrhea, abortion, short birth interval, amenorrhea, stenosis, gastroesophageal reflux disease, nausea, otalgia, and heartburn. We excluded pregnant patients who were younger than 12 years of age and those older than 19 , those without nutritional screening, and those without clinical files or with incomplete files.

Frequencies for categorical variables were obtained, as well as averages and standard deviations for non-categorical variables and the Chi-square test and Spearman correlation to establish differences in pre-gestational nutritional status and obstetric complications. The statistical analysis was performed using SPSS v.22 (SPSS Inc., Chicago, IL, USA). The study was conducted following all ethical and legal aspects of the Guidelines of the General Health Law on Health Research Aspects ${ }^{15}$ and with the authorization of the Ethics Committee of the institution (Gl14-008).

\section{Results}

Of a total of 148 pregnant adolescents with an average age of $17.4 \pm 1.34$ years, $91.2 \%$ were dedicated to house chores, while $8.8 \%$ were students. In addition, $61.8 \%$ of participants reported to be living in consensual unions, $27.7 \%$ were single, and $9.5 \%$ were married. About $64.2 \%$ had finished junior high school. Concerning pre-gestational status, $34.5 \%$ were identified with low weight, $33.8 \%$ with normal weight, and $31.8 \%$ were overweight and obese (Table 1).

Out of the total of adolescents studied, $75.6 \%$ presented one or more obstetric complications, while $24.4 \%$ did not present any complications. Among the observed complications, $26.4 \%$ of pregnant adolescents presented 
Table 1. Anthropometric characteristics of the studied population

\begin{tabular}{|l|c|}
\hline Variable & Average \pm DE \\
\hline Age (years) & $17.4 \pm 1.34$ \\
\hline Pre-gestational weight $(\mathrm{kg})$ & $58.6 \pm 17.6$ \\
\hline Height $(\mathrm{m})$ & $1.57 \pm 0.06$ \\
\hline Pre-gestational BMI $\left(\mathrm{kg} / \mathrm{m}^{2}\right)$ & $23.52 \pm 6.37$ \\
\hline Low weight, $\mathrm{n}(\%)$ & $51(34.5)$ \\
\hline Normal, $\mathrm{n}(\%)$ & $50(33.8)$ \\
\hline Overweight and obese, $\mathrm{n}(\%)$ & $47(31.8)$ \\
\hline
\end{tabular}

BMI: body mass index.

Table 2. Prevalence of fetal complications

\begin{tabular}{|l|c|}
\hline Fetal complications & n (\%) \\
\hline Anhydramnios & $20(31.3)$ \\
\hline Ruptured membrane & $6(9.4)$ \\
\hline DCP $\times$ EP & $5(7.8)$ \\
\hline Oligohydramnios & $2(3.1)$ \\
\hline PCPC & $1(1.6)$ \\
\hline Product with posterior urethral leaflets & $1(1.6)$ \\
\hline Pelvic product & $3(4.7)$ \\
\hline Transverse product & $1(1.6)$ \\
\hline Type 0 RCIU & $2(3.1)$ \\
\hline Type 1 RCIU & $6(9.4)$ \\
\hline RPDM & $11(17.2)$ \\
\hline Macrosomia & $2(3.1)$ \\
\hline Fetal suffering & $1(1.6)$ \\
\hline Probable intestinal malformation & $1(1.6)$ \\
\hline Spina bifida & $1(1.6)$ \\
\hline Absence of nasal bone & $1(1.6)$ \\
\hline & $n=148$ \\
\hline
\end{tabular}

fetal complications, the most significant being anhydramnios with $31.3 \%$, PMR with $17.2 \%$, and type 1 IUGR with $9.4 \%$ (Table 2). Moreover, $66.2 \%$ presented maternal complications including GDM (22.8\%), IVUB (12.4\%), and dysuria (19.3\%) (Table 3).
Table 3. Prevalence of maternal complications

\begin{tabular}{|c|c|}
\hline Maternal complications & n (\%) \\
\hline Anemia & $3(2.1)$ \\
\hline Cardiac arrhythmia & $1(0.7)$ \\
\hline Asthma & $2(1.4)$ \\
\hline Asymptomatic bacteriuria & $1(0.7)$ \\
\hline Headache & $9(6.2)$ \\
\hline DM ketoacidosis & $1(0.7)$ \\
\hline Cholecystolithiasis & $1(0.7)$ \\
\hline Condylomatosis & $4(2.8)$ \\
\hline Constipation & $1(0.7)$ \\
\hline Diarrhea & $1(0.7)$ \\
\hline Dysuria & $15(10.3)$ \\
\hline DM1 & $2(1.4)$ \\
\hline DMG & $33(22.8)$ \\
\hline Edema M. I. & $1(0.7)$ \\
\hline Multiple pregnancies & $1(0.7)$ \\
\hline Constipation & $6(4.1)$ \\
\hline Phosphenes & $3(2.1)$ \\
\hline Hypothyroidism & $4(2.8)$ \\
\hline Lumbar disc herniation & $1(0.7)$ \\
\hline Gestational hypertension & $12(8.3)$ \\
\hline Int the CHOS & $5(3.4)$ \\
\hline IVUB & $18(12.4)$ \\
\hline Leukorrhea & $9(6.2)$ \\
\hline Abortion & $1(0.7)$ \\
\hline Period I C & $1(0.7)$ \\
\hline Class II RCTG & $1(0.7)$ \\
\hline Amenorrhea & $1(0.7)$ \\
\hline E. coli & $1(0.7)$ \\
\hline Stenosis & $1(0.7)$ \\
\hline Umbilical vein persistence & $1(0.7)$ \\
\hline ERGE & $1(0.7)$ \\
\hline Nausea & $2(1.4)$ \\
\hline \multirow[t]{2}{*}{ Pyrosis } & $1(0.7)$ \\
\hline & $\mathrm{n}=148$ \\
\hline
\end{tabular}

When relating complications with pre-gestational nutritional status, statistically significant differences were observed $(p<0.05)$. Patients with normal weight 
Table 4. Pre-gestational nutritional status and maternal and fetal complications

\begin{tabular}{|l|c|c|c|c|}
\hline Pre-gestational nutritional status & Low weight (\%) & Normal weight (\%) & Overweight and obese (\%) & p-value \\
\hline Maternal complications & 21.4 & 39.8 & 38.8 & 0.000 \\
\hline Fetal complications & 30.8 & 33.3 & 35.9 & 0.779 \\
\hline$p \leq 0.05$ & & & $n=148$ \\
\hline
\end{tabular}

Table 5. Association between pre-gestational nutritional status and maternal and fetal complications

\begin{tabular}{|l|c|c|c|c|}
\hline Pre-gestational nutritional status & Low weight (\%) & Normal weight (\%) & Overweight and obese (\%) & p-value \\
\hline $\begin{array}{l}\text { Fetal complications } \\
\text { Ruptured membrane }\end{array}$ & 0.0 & 16.7 & 83.3 & 0.019 \\
\hline Maternal complications & & & & \\
\hline Gestational hypertension & 16.7 & 8.3 & 75.0 & 0.003 \\
$\quad$ Hypothyroidism & 0.0 & 0.0 & 100 & 0.012 \\
\hline DMG & 3.0 & 30.3 & 66.7 & 0.000 \\
\hline p $<0.05$ & & & & $n=148$ \\
\hline
\end{tabular}

presented a higher tendency to present maternal complications $(39.8 \%)$ ( $p=0.000)$. Within fetal complications, no significant differences were observed since none of the groups presented any complications (Table 4).

Moreover, out of all fetal complications, only the ruptured membranes presented significant data with pre-gestational nutritional status; the vast majority were among those patients in the overweight and obese group (83.3\%) ( $p=0.008)$. Regarding maternal complications, significant data between gestational hypertension and pre-gestational nutritional status were observed, especially in patients in the overweight and obese group, which presented a greater prevalence $(75.0 \%)(p=0.003)$; additionally, the prevalence of hypothyroidism and pre-gestational nutritional status in the same group of patients was $100 \%(p=0.012)$, and GDM had a prevalence of $66.7 \%(0.000)$ (Table 5).

\section{Discussion}

During the adolescent stage, special attention ought to be placed in health care since it is a developing stage. Evidence shows that a poor health condition alters the uterus environment, which can affect fetal development during pregnancy. Therefore, adolescents must maintain a good lifestyle, one that ensures optimal growth before and during this stage. Otherwise, lactation will become affected, causing a loss of lean body mass, in addition to impacting the product's health at birth ${ }^{16,17}$.

A deficient nutritional status and bad dietary habits lead to malnutrition during the adolescent and young adult stages, thus severely altering health and increasing morbidity rates. Another consequence of malnutrition is newborns with nutritional deficiencies and an increase in diseases, which is usually a result of poor dietary habits by the mother ${ }^{18}$.

Several studies have shown that extreme thinness or low $\mathrm{BMI}$ of the mother is one of the leading causes of low weight at birth in developing countries. This is linked to IUGR, neonatal morbidity, and mortality and delays in growth during the preschool stage ${ }^{19}$.

The main complications presented in adolescents within this study were anhydramnios, PMR, type 1 IUGR, GDM, IVUB, and dysuria. Similar results are observed in Peru in pregnant adolescents, finding a higher prevalence of gestational diabetes ${ }^{20}$. However, contrary to this investigation, in a study conducted with 600 pregnant women at the Department of Perinatal Medicine at the High Specialty Medical Unit of the Gynecological-Obstetric Hospital of Guadalajara, the main complications were type 1 and type 2 diabetes, hypertension, and renal alterations ${ }^{21}$. 
In all studies analyzed to date, there is some type of diabetes present; nevertheless, there are a greaternumber of complications among the Mexican population, which could be a result of the characteristics of the type of high-carb diet, which is consumed in Mexico.

Quintero et al. (2010) conducted a study in three health-care institutions in Colombia and found that $21.3 \%$ of pregnant adolescents presented low weight; yet, no relation was found with any obstetric complica$t_{i o n}{ }^{22}$. The results of this study differ from those previously proposed since they found a more significant number of adolescents with malnutrition (34.5\% low weight and $31.8 \%$ overweight), and important data were found that overweight patients showed a higher predisposition to suffer from a maternal complication (0.000).

Similar results were observed in pregnant patients in Nicaragua, where researchers found that patients with obesity were more likely to develop maternal complications $(p=0.01)^{23}$. This could be a result of the sample size utilized, or the region where the studies were conducted since the type of diet or access to food the patients may have could be different.

This research showed that $31.8 \%$ of pregnant adolescents considered overweight and obese developed some type of maternal complication; however, in Spain, the results were different, where researchers found that pregnant adolescents with normal weight (37.7\%) had a higher probability of developing a maternal complication (hypertension and gestational diabetes) $(p=0.001)^{24}$.

When observing each complication individually, this study found that over $80 \%$ of pregnant overweight adolescents presented a ruptured membrane, contrary to a study conducted in Nicaragua, where pregnant adolescents with obesity increased the risk of macrosomia $(p=0.0001)$ in the newborn ${ }^{23}$. Despite presenting different fetal complications, we can observe that there is a significant risk of affecting the newborn due to a poor diet by the mother in both populations.

The present study showed that over $60 \%$ of overweight patients presented gestational diabetes. When compared to similar studies, we discovered that this tendency also existed in Spain, where one of the main complications present in pregnant patients with obesity or low weight was gestational diabetes $(p=0.001)^{24}$. Similar data are observed in pregnant patients in Greece, where over $15 \%$ of them developed gestational diabetes during pregnancy $(p=0.007)^{25}$. Compared to Nicaragua, there is a greater prevalence of gestational diabetes in obese patients $(p=0.0002)^{23}$.

Moreover, gestational hypertension was also present in pregnant overweight patients $(75 \%)$ in this study, showing significant results $(p=0.003)$. When compared to other studies, it was noted that, in Spain, one of the main complications was gestational hypertension (3.4\%), and there were significant differences among pregnant overweight patients $(p=0.001)^{24}$. At the same time, in Tegucigalpa, $7.4 \%$ of pregnant patients presented obesity, and four of them also presented gestational hypertension $(0.020)^{26}$. In Guadalajara, a statistically significant correlation between pre-gestational obesity and gestational hypertension was identified $(p=0.003)^{27}$. Pre-gestational obesity and gestational hypertension may lead to adverse results for the mother as well as for the neonate.

Finally, in our study, hypothyroidism was present in pregnant overweight patients (100\%), showing significant results $(p=0.012)$. In Spain, significant differences were observed between the group of women with morbid obesity and hyperthyroidism $(p=0.048)^{28}$. Similarly, in the Netherlands, hyperthyroidism was linked to maternal obesity before pregnancy $(p=0.05)^{29}$. In our study, the incidence of pre-gestational overweight women increased the risk of maternal-fetal complications.

Therefore, it is important to consider nutrition in adolescents since it has been proven worldwide that women with obesity have a higher risk of presenting fetal and maternal complications ${ }^{30,31}$. The promotion of health during this stage is important to prevent the development of illnesses during pregnancy and to care for the health of the newborn, as well as to promote the consumption of a healthy diet, specifically during this stage of life.

Established results allow us to identify that the nutritional status of the mother-to-be is a risk factor for her health and that of the newborn. Therefore, a proper evaluation of pre-gestational nutritional status and a dietary orientation is fundamental, to promote a correct diet in adolescents before and during their pregnancy, meeting their nutritional needs, and reduce the risk of obstetric complications and/or complications during delivery.

Within the limitations of this study, findings show that there is a lack of studies of the Mexican population, making a proper comparison difficult. Furthermore, there are fewer studies that evaluate only adolescents.

The data obtained may be useful in the development and implementation of health programs aimed at integral and multidisciplinary attention to pregnant adolescents for the prevention of adolescent pregnancies, as well as implementing measures that improve the health services of pregnant adolescents, to obtain better obstetric and perinatal results. 


\section{Conclusion}

The results of this study show that pre-gestational nutritional status is linked to obstetric complications (maternal and fetal), which the pregnant adolescents presented. Thus, proper nutrition is essential, yet only one of many factors for a healthy pregnancy from start to finish. There are other factors which are just as important, if not more so. For this reason, prospective studies ought to be taken to a larger population to establish a direct relationship between nutrition and obstetric results in pregnant adolescents.

This implies greater care during the gestational stage due to the present nutritional risk factors; it is necessary to ensure the proper consumption of nutrients for the correct development and growth of the newborn and the mother.

The main risk factors for the development of obstetric complications observed among the studied population were malnutrition (low weight, overweight, and obesity) and age of the population; therefore, greater attention through prenatal control is necessary to avoid complications.

\section{Funding}

This research did not have any external source of financing.

\section{Conflicts of interest}

The authors declare that they have no conflicts of interest.

\section{Ethical disclosures}

Protection of human and animal subjects. The authors declare that no experiments were performed on humans or animals for this study.

Confidentiality of data. The authors declare that they have followed the protocols of their work center on the publication of patient data.

Right to privacy and informed consent. The authors have obtained the written informed consent of the patients or subjects mentioned in the article. The corresponding author is in possession of this document.

\section{References}

1. Organización Mundial de la Salud. El Embarazo y el Aborto en la Adolescencia. Ginebra: Organización Mundial de la Salud; 1975. p. 583.

2. Gutiérrez JP, Rivera-Dommarco J, Shamah-Levy T, Villalpando-Hernandez S, Franco A, Cuevas-Nasu L, et al. Encuesta nacional de salud y nutricion 2012. In: Resultados Nacionales. $2^{\text {nd }}$ ed. Mexico: Instituto Nacional de Salud Pública; 2013.
3. Kaiser LL, Allen L. Position of the American dietetic association. Nutrition and lifestyle for a healthy pregnancy outcome. J Am Diet Assoc. 2002;102:1479-90.

4. Shabert JK. Nutrition during pregnancy and lactation. In: Mahan K, Escott-Stump S, editors. Krause's Food Nutrition and Diet Therapy. Philadelphia, PA: Saunders; 2004. p. 182-209.

5. López JT, Cárdenas VM, Interial MG, Justo R, Ríos MC. Evaluación nutricional en adolescentes embarazadas. Desarrollo Cientif Enferm. 2010:18:198-203.

6. Hernández CE, Hernández MG, Juárez ED. Embarazo en adolescentes y su nutrición. En: Terapia Nutricia Médica en Ginecología y Obstetricia. México: McGraw-Hill; 2011. p. 256-63.

7. Bertoldi-Nucci L, Schmidt MI, Bartholow-Duncan B, Costa-Fuchs S, Fleck ET, Santos-Britto MM. Nutritional status of pregnant women: prevalence and associated pregnancy outcomes. Rev Saúde Pública. 2001;35:502-7.

8. Sayuri AP, Fujimori E. Nutritional status and weight gain in pregnant women. Rev Latino Am Enfermagem. 2012;20:462-8.

9. Casanueva E, Kaufer-Horwitz M, Pérez AB, Arroyo P. Nutriología Médica. $3^{\text {rd }}$ ed. México: Médica Panamericana; 2008.

10. D’Avila AM, Bettiol H, De Souza L, Gurgel R, Dória ML, Ramos E, et al. Is adolescent pregnancy a risk factor for low birth weight? Rev Saúde Pública. 2013;47:11-9.

11. Gomella TL, Cunningham D, Eyal F, Zenk K. Neonatología. $5^{\text {th }}$ ed. México: Editorial Médica Panamericana; 2006.

12. Espinoza M, Rodríguez MM, Trejos ME. Caracterización de la adolescente embarazada atendida en la clínica Francisco Bolaños. Rev Med Costa Rica. 2009;66:21-5.

13. Vallejo J. Embarazo en adolescentes complicaciones. Rev Med Costa Rica. 2013;70:65-9.

14. World Health Organization. Maternal anthropometry and pregnancy outcomes. Bull World Health Organ. 1995;73:1S-98S.

15. Secretaria de Salud. Reglamento de la Ley General de Salud en Materia de Investigación Para la Salud. Secretaria de Salud; 1988. Available from: http://www.salud.gob.mx/unidades/cdi/nom/compi/rlgsmis.html. [Last accessed on 2016 Mar 21].

16. Hendrina de Boo, JH. The developmental origins of adult disease (Barker) hypothesis. Aust N Z J Obstet Gynaecol. 2006;46:4-14

17. Jee PC, Abu UT, Arju AB, Labrique MR. Pregnancy and lactation hinder growth and nutritional status of adolescent girls in rural Bangladesh. J Nutr. 2008;138:1505-11.

18. Victora C, Adair L, Fall C, Hallal P, Martorell R, Richter L, et al. Maternal and child undernutrition: consequences for adult health and human capital. Lancet. 2008:371:340-57.

19. Black R, Allen L, Bhutta Z, Caulfield L, de Onis M, Ezzati M, et al. Maternal and child undernutrition: global and regional exposures and health consequences. Lancet. 2008;371:243-60.

20. Okumura, J, Maticorena, D, Tejeda, J, Mayta-Tristán, P. Embarazo adolescente como factor de riesgo para complicaciones obstétricas y perinatales en un hospital de Lima, Perú. Rev Bras Saude Mater Infant. 2014;14:383-92.

21. Hernández-Higareda S, Pérez-Pérez $O$, Balderas-PeñaL, Martínez-Herrera B Salcedo-Rocha A, Ramírez-Conchas E. Enfermedades metabólicas asociadas a sobrepeso y obesidad pregestacional en mujeres mexicanas que cursan con embarazo de alto riesgo. Cirugía Cirujanos. 2017;85:292-8.

22. Quintero R, Muñoz MN, Álvarez LE, Medina GA. Estado nutricional y seguridad alimentaria en gestantes adolescentes. Invest Educ Enferm. 2010;28:204-13.

23. Valdés $E$, Bencosme N. Frecuencia de obesidad y su relación con algunas complicaciones maternas y perinatales en una comunidad indígena. Rev Cubana Endocrinol. 2015;26:238-45.

24. De la Plata M, Pantoja M, Frías Z, Rojo S. Influencia del índice de masa corporal pregestacional y ganancia ponderal materna en los resultados perinatales materno-fetales. Rev Cubana Obstet Ginecol. 2018;44:1-9.

25. Vassilaki M, Chatzi L, Vaggelis G, Philalithis A, Giorgos K, Koutis A, et al. Pregestational excess weight, maternal obstétrics complicationes and mode of delivery in the Rhea cohort in Crete. Eur J Public Health. 2015;25:632-7.

26. Lozano L, Cueva J, Espinoza I. Hipertensión arterial y diabetes gestacional en pacientes obesas y con sobrepeso, Centro de Salud Alonso Suazo, Tegucigalpa. Rev Med Hondur. 2017;85:3-4.

27. Hernandez S, Perez O, Balderas LM, Martínez B, Salcedo AL, Ramírez R. Maternal metabolic diseases related to pre-pregnancy overweight and obesity in Mexican women with high risk pregnancy. Cirugía Cirujanos. 2017;85:292-8.

28. Rodríguez C, Álvarez E, Rodríguez R, Pérez M, Alves M. Obesidad mórbida y desenlaces materno-fetales. Ginecol Obstet Mex. 2019:87:647-59.

29. Collares F, Korevaar T, Hofman A, Steegers E, Peeters R, Jaddoe V, et al. Maternal thyroid function, prepregnancy obesity and gestational weight gain the generation R study: a prospective cohort study. Clin Endocrinol. 2017;87:799-806.

30. Velie E, Shaw G, Malcoe L, Schaffer D, Samuels S, Todoroff K. Understanding the increased risk of neural tube defect-affected pregnancies among Mexico-born women in California: immigration and anthropometric factors. Paediatr Perinat Epidemiol. 2006;20:219-30.

31. Leddy M, Power M, Schulkin J. The impact of maternal obesity on maternal and fetal health. Rev Obstet Gynecol. 2008;1:170-8. 